\title{
Breve compêndio conceitual e metodológico da Psicodinâmica do Trabalho e da Psicossociologia
}

\author{
Lucas Martins Soldera \\ Universidade Estadual de Maringá (Maringá, PR, Brasil)
}

O objetivo do presente artigo foi expor de forma sucinta algumas distinções conceituais e metodológicas da Psicossociologia e da Psicodinâmica do Trabalho, a fim de auxiliar na visualização de suas diversidades, na elucidação e na elaboração de uma possível intervenção. Para isso, utilizamo-nos de uma pesquisa teórica que contemplou um resgate do desenvolvimento teórico-conceitual de cada uma dessas abordagens. Foi construído um quadro metodológico para a Psicodinâmica do Trabalho e para a Psicossociologia embasado em obras referências de cada área. Acreditamos que este artigo, ao colocar ambas as teorias frente a frente com suas particularidades, deva contribuir no sentido de oferecer meios para que os próprios leitores possam escolher por suas preferências e afinidades, sem deixar de considerar a importância do diálogo teórico heterogêneo para as abordagens que compõem as Clínicas do Trabalho. Devemos ressaltar, ainda, a inviabilidade de se trabalhar com duas ou mais metodologias em uma mesma intervenção. Concomitantemente, ao se conhecer mais sobre as possibilidades de atuação do profissional psicólogo, poder-se-á contribuir também para o desenvolvimento da Psicologia do Trabalho.

Palavras-chave: Psicologia do trabalho, Clínicas do trabalho, Psicodinâmica do trabalho, Psicossociologia.

Brief summary of conceptual and methodological distinctions between Work Psychodynamics and Psychosociology

The objective of the present article was to show in a brief way some conceptual and methodological distinctions of Work Psychodynamics and of Psychosociology, aiming at the visualization of its diversities, clarification, and elaboration of a possible intervention. For this, it was used a theoretical research which encompasses theoretical and conceptual development of each one of these approaches. Aiming at embracing this discussion, it was still built a methodological chart for the Work Psychodynamics as well as for the Psychosociology based on benchmark works of each area. Finally, we believe that this article, when comparing both theories, each one with their own particularities, may contribute by offering ways for the readers to choose their preferences and affinities. This was done, bearing in mind the importance of the heterogeneous theoretical dialogue for the approaches that compose the Work Clinics. Still, we need to highlight, according to this clinical proposal, the unviability of working with two or more methodologies in a specific intervention. Concurrently, when getting to know more about the possibilities of the professional psychologist's performance, we may contribute as well for the development of Work Psychology.

Keywords: Work psychology, Work clinics, Work psychodynamics, Psychosociology.

\section{Introdução}

$\mathrm{O}$ artigo constitui-se em um estudo teórico a partir das premissas da abordagem qualitativa. Segundo Demo (2000), a pesquisa teórica pode ser empregada como base na criação de condições para uma intervenção. Nesse sentido, trabalhamos diretamente com as ideias que embasam a proposta das Clínicas do Trabalho e se propõem a pensar "novas" formas de intervenção frente ao mundo do trabalho. Inicialmente fizemos alguns esclarecimentos sobre as clínicas para, somente depois, entrarmos em nossas discussões teóricas e metodológicas em Psicodinâmica do Trabalho e Psicossociologia.

Essas duas teorias estão contempladas dentro das Clínicas do Trabalho, que reúnem também outras abordagens (Ergologia e Clínica da Atividade) ${ }^{1}$ e diferentes pontos de vista: epistemológico, ontológico e metodológico. A proposta clínica não visa formular uma disciplina 
lapidada no que se refere ao trabalho; ao contrário, para ela a construção teórica deve acontecer concomitantemente e a partir da prática, para que, na discussão e no diálogo estabelecido entre elas - e suscitado por suas diferenças - cada uma se desenvolva ao seu modo.

Conferir "novas" leituras e análises do contexto do trabalho, bem como abrir "novas" perspectivas para a Psicologia do Trabalho em nosso país, é o intuito da proposta clínica, assim como o de nosso próprio artigo. Elas consideram, em primeiro lugar, as demandas do trabalhador, seja em relação à questão da saúde coletiva ou à da mobilização da subjetividade.

Ao colocarmos ambas as propostas teóricas em um mesmo artigo e considerar suas diferenças e proximidades, também podemos contribuir com os estudos das Clínicas do Trabalho, haja vista que "...o desenvolvimento da clínica do trabalho passa, portanto, por uma discussão de seus dispositivos, métodos e práticas” (Amado \& Lhuillier, 2014, grifo nosso²).

Quando isso ocorre, o desenvolvimento teórico e a constituição distinta de cada uma deve ser respeitado; por isso, a importância de referenciar conceitos, no intuito de localizar o leitor durante o texto. Lhuillier (2011) diz que é importante referenciarmos cada conceito e identificar ao leitor de onde vem a ideia exposta para elucidar a leitura, uma vez que trabalhamos com uma proposta clínica tão heterogênea.

Apesar de ambas as teorias possuírem o caráter clínico, em que as falas dos trabalhadores são as bases para atuações e análises, em relação à prática é inviável a utilização de dois métodos distintos em uma mesma intervenção, haja vista as diferenças epistemológicas, teóricas e metodológicas de cada uma.

Acreditamos, ainda, que o fato de colocarmos ambas as teorias em um mesmo artigo, realizando um paralelo entre alguns conceitos e aspectos metodológicos, possa auxiliar o leitor a identificar algumas preferências. Além disso, conhecer mais sobre possibilidades de atuação pode contribuir no desenvolvimento das práticas em Psicologia do Trabalho para além do caráter tecnicista que outrora dominou a atuação desse profissional. Destarte, acreditamos que a subdivisão adotada neste artigo - apresentando primeiramente a teoria que embasa o método e depois a metodologia especificamente - contribui para a visualização desses aspectos.

Gostaríamos de deixar explícito que utilizamos como modelo de intervenção em Psicodinâmica do Trabalho os estudos de Mendes e Araújo (2012) - embasados nas ideias originais dejourianas - os quais trazem algumas possibilidades vinculadas ao contexto brasileiro no emprego desse método. Já para o modelo de intervenção em Psicossociologia utilizamos os estudos de Pagès (1976), expostos no livro A vida afetiva dos grupos: esboço de uma teoria da relação humana ${ }^{3}$.

Respeitando as questões levantadas de início, podemos traçar o objetivo deste artigo, que foi o de expor a distinção conceitual e metodológica da Psicossociologia e da Psicodinâmica do Trabalho, a fim de auxiliar na elucidação e na elaboração de uma possível intervenção.

Para tanto, a seguir foi exposto aquilo que denominamos de um breve panorama conceitual e metodológico sobre a Psicodinâmica do Trabalho e sobre a Psicossociologia.

\footnotetext{
2 Grifamos essa passagem da citação para explicar a existência de uma diferença na denominação. No Brasil, chamamos de Clínicas do Trabalho a proposta que hoje forma um dos eixos constituintes da Associação (ou Sociedade) Brasileira de Psicologia Organizacional e do Trabalho - SBPOT. No entanto, na França, o que chamamos de Clínicas do Trabalho também recebe o nome Clínica do Trabalho. Isso não acontece no Brasil porque a Psicodinâmica do Trabalho tem adotado essa denominação, no singular, para nomear seu método de intervenção e análise. O nome completo desta última é Clínica Psicodinâmica do Trabalho (CPDI), que tem suas raízes na proposta dejouriana e vem sendo desenvolvida desde 1980 e, ao poucos, foi ganhando corpo, voltando-se cada vez mais para o caráter clínico, até ficar reconhecida por aqui como Clínica do Trabalho.

3 Existem outras formas para condução dessas metodologias, tanto a psicodinamicista quanto a psicossociológica; contudo, não é a proposta deste artigo dissecar todas as possibilidades de intervenção, haja vista sua viabilidade. Para isso, foram adotadas referências específicas que possibilitam duas formas de intervenção, visando aproximar o leitor de uma possível postura clínica, expandindo assim a atuação da Psicologia do Trabalho para além do estereótipo organizacional/tecnicista.
} 


\section{Psicodinâmica do Trabalho}

A Psicodinâmica do Trabalho teve muitas influências teóricas durante tudo seu desenvolvimento. A constituição de seu próprio nome nos conta um pouco dessas influências. Christophe Dejours começou a definir a Psicodinâmica do Trabalho a partir de 1980, trazendo consigo influências da Psicopatologia do Trabalho, vertente voltada para Psiquiatria. Nesse percurso, autores como Sivadon e Le Guillant, considerados os pais da Psicopatologia do Trabalho, foram cruciais para o início do entendimento da relação trabalho/doença.

No início dos anos 1990, mesmo considerando a importância da Psicopatologia do Trabalho, Dejours deixa de empregar essa denominação e passa a utilizar Psicodinâmica do Trabalho, em decorrência do desenvolvimento dessa teoria e da proximidade de seus estudos mais recentes com a Psicanálise e a Ergonomia. Essa proximidade possibilitou a expansão do entendimento da relação trabalho/doença para a relação trabalho/sofrimento.

Pensar a relação trabalho/sofrimento para Dejours (1992a) é pensar a relação homem/trabalho, uma vez que o sujeito (homem) da Psicodinâmica é o sujeito do sofrimento, enquanto o trabalho é o principal mediador entre as instâncias psíquica e social desse homem (aspecto privilegiado da relação entre a esfera inconsciente e a esfera social).

Esse sujeito do sofrimento pode ser entendido, segundo Ferreira (2013), como alguém que vivencia afetivamente a situação. A afetividade seria a forma como o corpo vivencia o contato com o mundo, funcionando como base da subjetividade e da constituição do sujeito. Dessa forma, experienciar afetivamente o sofrimento envolvido no trabalho possibilita a conscientização do real conhecimento sobre o mundo do trabalho: "...o real revela-se àquele que pesquisa ou trabalha através do modo afetivo do sofrimento” (Dejours, 2007, p. 17).

No decorrer histórico do desenvolvimento dessa teoria, o autor passa a conceber que não é o trabalho quem causa doenças nas pessoas mas a forma como esse trabalho está organizado. Alguns conceitos foram essenciais para se chegar a tal elucidação, entre eles: normalidade, sofrimento no trabalho (criativo e patogênico) e mecanismos de defesa (Dejours, 1992a).

A definição de normalidade pode ser encontrada como o equilíbrio psíquico entre constrangimento do trabalho desestabilizante ou patogênico e defesas psíquicas. Assim, por sua vez, esse equilíbrio seria o resultado de uma regulação que requer estratégias defensivas especiais, elaboradas pelos próprios trabalhadores; entretanto, a normalidade conquistada e conservada pela força é trespassada pelo sofrimento (Vieira, Mendes, \& Merlo, 2013).

O sofrimento não está restrito apenas ao caráter pejorativo ou de senso comum. Ele pode advir do corpo (ações mecânicas de ordem ergonômica) ou do psiquismo (insatisfação em relação aos significados das atividades e falta de reconhecimento). O sofrimento relacionado ao trabalho, para Dejours (1992a), pode ser causador de problemas e doenças mentais - sofrimento patogênico - ou mobilizador, no próprio sujeito, de melhorias para sua vida - sofrimento criativo.

Já as estratégias defensivas podem ser entendidas como estratégias elaboradas pelos trabalhadores para enfrentar mentalmente o trabalho e manter o equilíbrio psíquico (normalidade). Passou-se a buscar a origem do sofrimento proveniente da relação sujeito/organização do trabalho e a compreensão desse sofrimento e das estratégias defensivas (sejam elas individuais ou coletivas) ${ }^{4}$.

É no conflito entre organização do trabalho e funcionamento psíquico que está a fonte de sofrimento. No entanto, nesse conflito está também a chave das possibilidades de análise. As estratégias defensivas variam de acordo com a situação, podendo ser classificadas, como aponta Mendes (2007), em sobrecarga de trabalho, servidão voluntária e submissão voltada à manutenção do conforto, e práticas violentas contra si, contra o outro ou contra o patrimônio.

4 Para uma maior elucidação sobre o conceito de estratégias defensivas, consultar Mendes (2007). 
O que inicialmente pode servir como estratégias aos trabalhadores para se manterem em um estado de equilíbrio contra as adversidades da forma como o trabalho está organizado, em médio e longo prazos pode levar essas pessoas a um estado de torpor psíquico. Percebe-se um embotamento pessoal e uma despolitização, causados pela falta de poder em intervir na "organização de seu trabalho".

Em 1980, no livro Travail, usure mentale: essai de psychopathologie du travail ${ }^{5}$, Dejours já elucidava a necessidade de um lugar de discussão entre trabalhadores legitimado pelo coletivo, onde se sintam confortáveis para problematizar as questões do trabalho, de forma que a palavra (necessariamente autêntica) circule livremente. Por conseguinte, poderá avançar em prol da saúde mental no trabalho. Os contornos desse método começam a ganhar maior nitidez com a publicação do Seminaire Interdisciplinaire de Psychopathologie du Travail, em 1993, que fala em uma clínica no contexto do trabalho e mostra a preocupação científica do autor com o método empregado. $\mathrm{O}$ método clínico que o autor veio desenvolvendo adquire seus últimos delineamentos com a publicação do livro Suicide et travail: que faire? de 2010, de autoria de Dejours e Bègue. Neste livro, os autores confirmam a abertura de espaços, que já vinham sendo construídos, para repensar a metodologia utilizada até então. Eles lançam observações clínicas sobre um determinado caso e utilizam vários casos clínicos para entender o que está se passando dentro do contexto laboral. Essas observações permitem analisar relações subjetivas do trabalho advindas de situações clínicas psicopatológicas.

Delimita-se aí uma clínica psicodinâmica. Desde então, a Clínica Psicodinâmica do Trabalho (CPDI) tem-se mostrado, para a Psicodinâmica do Trabalho, uma das formas mais indicadas para se trabalhar em todas essas questões.

Temos para Psicodinâmica do Trabalho um trabalho constituinte do sujeito, que ocupa lugar central no processo de subjetivação, o que torna necessário entender a organização do trabalho para compreender as vivências subjetivas, de onde tanto sofrimento e prazer podem surgir.

Entretanto, se a via de acesso ao reconhecimento for obstruída (e é isso que observamos cada vez mais nos processos de trabalho contemporâneos), o sofrimento não pode mais ser transformado em prazer e o trabalho não pode mais encontrar sentido. Caminharemos em direção à patogenia, de tal modo que só restará ao trabalhador o uso das estratégias defensivas para tentar manter sua integridade sociopsíquica.

\section{Método da clínica psicodinâmica do trabalho (ou clínica do trabalho) - CPDI}

Se optarmos por utilizar esse método clínico psicodinamicista, devemos alertar que Dejours (1992a) relata a necessidade e importância na criação de espaço de liure circulação da palavra para a prática de intervenção da pesquisa, que consiste em conscientizar os trabalhadores para que eles possam desempenhar a modificação efetiva desse trabalho. Portanto, seu objeto de estudo consiste no sujeito do sofrimento em relação com seu trabalho.

A CPDI, composta também pelos espaços de livre circulação da palavra, constitui uma técnica que acompanha a dinâmica imprescritível do trabalho, já que a verdade sobre a organização do trabalho não é algo que pode ser encontrado, pois ela é construída em um coletivo, o que dá corpo a uma clínica da prática. A técnica permite mostrar a importância do trabalho, da dinâmica do reconhecimento nos destinos do sofrimento, sejam eles direcionados para saúde, sejam para o adoecimento. Isso tem sido feito por meio do desvendar das vivências subjetivas dos trabalhadores. $O$ trabalhador, ao elaborar suas vivências (e até mesmo dividir

5 Dessa obra referência de Dejours, utilizamos sua 5ạ edição, traduzida por Ana Isabel Paraguay e Lúcia Leal Ferreira, publicada pela editora Cortez no ano de 1992. 
suas experiências com o coletivo), constrói uma análise que lhe possibilita entender melhor o trabalho e que lhe permite modificá-lo.

Contudo, para se chegar a esse objetivo, a CPDI exige qualificação teóricometodológica do pesquisador-clínico, visando articular teoria do sujeito e teoria do social com uma condução ética centrada no outro. Requer desse pesquisador escutar o que não foi dito, o oculto, e o que foi silenciado pela organização do trabalho numa tarefa coletiva, a fim de desvendar o sofrimento e de possibilitar mobilização subjetiva em uma cooperação que levará a uma ação de transformação dessa organização do trabalho.

Esse dispositivo tem como referência os estudos iniciais de Dejours sobre Psicopatologia do Trabalho, utilizando-os como base; Mendes e Araújo (2012) trazem alguns procedimentos que não visam estabelecer um manual de aplicação da técnica, mas dar sentido e certa ordem ao fazê-lo.

Segundo Mendes e Araújo (2012), esse método permite vincular outras técnicas para a pesquisa, como entrevistas individuais, coletivas, escalas, entre outros, visando ampliar a prática psicodinamicista, considerando a escuta sensível indissociável da subjetividade do sujeito, tornando-se, por isso, uma prática repleta de compromissos éticos, sociais e políticos, com o envolvimento afetivo tanto do pesquisador como do trabalhador. Essa é uma prática que pretende alcançar a transformação da organização do trabalho e o engajamento com a luta dos trabalhadores pela saúde mental.

Para realizar o trabalho, é necessária a constituição de dois grupos, o coletivo de pesquisa, composto por um grupo de trabalhadores e pesquisador(es), e o coletivo de clínicos (denominado anteriormente por Dejours de "coletivo controle"), composto por um grupo de pesquisadores. Vale considerar, ainda, que a mobilização subjetiva do pesquisador-clínico é condição essencial para o desenvolvimento da intervenção.

Outras condições, explicitadas por Mendes e Araújo (2012) para realizar a CPDI, estão, a seguir, brevemente descritas:

1. Organização da pesquisa: a escolha do local onde se desenvolverão os encontros (geralmente vinculado ao trabalho), a definição dos horários e dias, a explicação da importância da continuidade do trabalho para constituição de vínculos e transferência e o planejamento da condução das sessões;

2. Construção e análise da demanda: aceitação ou não da demanda e participação do pesquisador em vários encontros formais e informais para se aproximar do coletivo de pesquisa. Nesta fase, podem ser utilizados instrumentos psicométricos para levantamento de fatores de risco de adoecimento no trabalho;

3. Instituição das regras de conduta do coletivo de pesquisa e do coletivo de clínicos: estabelecimento de aspectos éticos em relação à aceitação das diferenças e respeito pelo outro, visando estimular a fala;

4. Constituição do espaço da fala e da escuta: espaço onde o pesquisador funciona como interlocutor, a fim de abrir espaços no discurso para a relação prazer/sofrimento no trabalho. Todas as suas observações e interpretações se dão a partir das vivências dos trabalhadores;

5. Estruturação do memorial: baseado na fala dos trabalhadores, construído no final de cada sessão e retomado no início da seguinte. Para estruturá-lo, utiliza-se uma técnica que visa organizar o material coletado nas sessões coletivas em eixos temáticos e que recebe o nome de Análise Clínica do Trabalho (ACT) - técnica inspirada nos núcleos de sentido de Bardin (1970) - em que o pesquisador coloca, também, sua interpretação sobre o dito, no intuito de conferir qualidade e significado ao discurso;

6. Restituição e deliberação: o tema da sessão anterior é retomado no início da sessão e, se pertinente, os termos técnicos são discutidos e as interpretações, explicadas. Esse é um espaço para acrescentar, discordar e sugerir ações para resoluções de conflitos; 
7. Diário de campo e registro dos dados: pode ser feito por meio de gravações (se aceito pelo grupo) ou registro das falas, de memorial de cada sessão e diário de campo. Neles são abordados os resultados das observações clínicas, eventos não verbais, fatos ocorridos e relação entre pesquisador e seus sentimentos evocados nos encontros;

8. Supervisão: visa à qualificação do pesquisador-clínico, bem como a fazer com que a própria subjetividade trabalhe de modo a entender a subjetividade do outro. $O$ pesquisador deve trabalhar suas próprias resistências e defesas. Além do memorial, ele deve fazer o diário de campo relatando suas impressões de como foi afetado. Esses registros são a base para a discussão no coletivo de clínicos;

9. Apresentação dos relatos: o relatório final sobre a ACT deve ser construído em conjunto, pelo coletivo de pesquisa e pelo coletivo de clínicos, e apresentado ao fim;

10. Avaliação: pode ser mensal e/ou depois de três meses do término da intervenção. É realizada a partir de entrevistas coletivas, a fim de averiguar a mobilização ocorrida no coletivo e o engajamento para mudança e a condução; deve averiguar, também, a manutenção do espaço de palavra e escuta após a saída do pesquisador.

Essas etapas - apesar de atualizadas e teoricamente desenvolvidas - estão intimamente relacionadas com a metodologia inicial proposta por Dejours (1980) em Travail, usure mentale, em que o autor também explicita algumas etapas a serem adotadas para condução desse método.

\section{Psicossociologia}

No decorrer de sua história, a Psicossociologia teve muitas influências, desde Kurt Lewin nos Estados Unidos passando pelo Instituto Tavistok na Europa. Contudo, suas bases teóricas sempre estiveram vinculadas à Psicanálise e à Sociologia, a ponto de Gaulejac (2001) afirmar que:

Ela só pode existir num entre-dois, num inter-dito, numa relação conflituosa entre duas lógicas causais e irredutíveis uma à outra. Há algo de irreconciliável entre o "psíquico" e "social". Isso conduz não a escolher seu terreno, como alguns preconizam, mas a se situar num campo e "conversar" com todos aqueles que sofrem do dogmatismo monodisciplinar (p. 46).

A proposta psicossociológica é de uma pesquisa/intervenção, em que o saber é produzido pelos atores que participam da ação (prática), atores estes que possuem particularidades e diferentes competências que não devem ser esquecidas. $O$ saber é produzido a partir de uma análise social das práticas em situações concretas visando à transformação (Bendassolli \& Soboll, 2011).

Segundo Carreteiro e Barros (2014), ela não possui objeto próprio, haja vista que todo objeto é dinâmico, contudo se pauta pela inserção do sujeito no contexto da vida cotidiana em grupos, organizações e instituições.

Há um interesse geral pelo sujeito e seu meio ambiente, onde o trabalho corresponde a um aspecto desse contexto, ao invés de constituir-se um objeto específico, como na Psicodinâmica do Trabalho. Aqui, o trabalho pode ser entendido como essencial na e para a sociedade, entretanto não ocupa local único na organização do drama humano, ele é um elemento constituinte. Talvez seja por isso que, apenas recentemente, a Psicossociologia tenha dado um foco maior aos estudos vinculados ao trabalho - diferentemente da Psicodinâmica do Trabalho, que sempre adotou o trabalho como seu norte principal.

Esse movimento possibilita a ampliação do campo de pesquisa, em que os psicossociólogos voltam-se para a vida das organizações e a seus alicerces afetivos, imaginários e inconscientes, já que: 
...os sujeitos humanos não se encontram ligados apenas a uma função e a um trabalho, eles estão, em maior ou menor grau, ligados a um sistema mediador entre o indivíduo e a sociedade, o grupo, a organização e a instituição (Amado \& Enriquez, 2011, p. 104).

Visa-se à compreensão dos processos grupais, organizacionais e institucionais, que conduzem às mudanças sociais, priorizando a relação indivíduo/sociedade, independentemente de onde essa relação se dê.

Gaulejac (2001) contribui nesse sentido, expondo que os objetos de pesquisa e intervenção da psicossociologia são “....as relações entre 'o' social - que apresenta dimensões emocionais, subjetivas, afetivas e inconscientes - e 'o' psiquismo, pela língua, pelo simbólico e pela sociedade..." (p. 37).

O sujeito é produto do social, entretanto não é um sujeito passivo dos determinismos sociais. Essa relação encontra-se na base da compreensão do mundo do trabalho e do sujeito trabalhador; daí a importância da experiência dos trabalhadores na compreensão e elaboração de conhecimentos de seu desenvolvimento nos processos coletivos.

A Psicossociologia visa à concepção de indivíduos autônomos e criadores de história e tende a avançar com os estudos da proposta da Clínica do Trabalho, inserindo a pulsão e a libido atuando sobre as relações e situações sociais. Dessa forma, Lèvy, Nicolaï, Enriquez e Dubost (2001) consideram que ela tende às transformações sociais e o remanejo psíquico; aqui, as modificações devem ser acompanhadas por mudanças no psiquismo do ator, assim como por mudanças no modo de funcionamento dos grupos.

Tanto atores sociais ${ }^{6}$ como pesquisadores tendem a atuar de forma cooperativa, tendo em vista o desenvolvimento social por meio de uma democracia ativa e sem distinção de papéis.

\section{Método da intervenção psicossociológica}

Foi Max Pagès quem primeiro empregou a expressão intervenção psicossociológica para designar um método específico, em 1968, no seu livro La vie affective des groupes. Nesse artigo, utilizamos a versão brasileira publicada em 1976, A vida afetiva dos grupos: esboço de uma teoria da relação humana, para nos referirmos às contribuições da referida obra.

Tanto para a Psicossociologia, como para a Psicodinâmica do Trabalho, a pesquisaação se tornou uma referência para intervenções, uma vez que esta propõe um envolvimento do pesquisador, atuando como ativo na transformação dos processos organizacionais.

Esse tipo de pesquisa se manteve como metodologia dominante, embora não mais restrita às experimentações; ela se expandiu, também, para os problemas reais de grupos e organizações em situações concretas; o objetivo deixou de ser prerrogativa do interventor e passou a ser construído pelo coletivo-cliente na ação. Essa "nova" postura fez com que o modelo clássico de pesquisa, em que o pesquisador detém o conhecimento, fosse abandonado, abrindo caminho para a autonomia e as mudanças sociais. $O$ conflito entre sujeito $\mathrm{e}$ organização torna-se parte essencial do trabalho.

As teorias psicossociológicas predominantes até esse momento correspondiam ao modelo epistemológico de pesquisa científica, o que dificultava acomodar tais teorias na perspectiva analítica/clínica. Nesse sentido, a perspectiva da pesquisa-ação se mostra "limitada", já que propõe diferenças de papéis no campo da intervenção.

A perspectiva clínica na intervenção, requisitada pela Psicossociologia, mantém o caráter científico-metodológico e as estratégias de pesquisa bem definidas, abrindo-se para o

6 Aos atores sociais, Sainsaulieu (2005) nos oferece uma definição pluridimensional: “...a da luta constitutiva do futuro, a das negociações nas relações de poder criadoras de racionalidade, a das conciliações intersubjetivas fonte de sentido e de cultura, e por fim a dos compromissos argumentados entre económico e social" (p. 16). 
entendimento de que o dispositivo tem que ser inventado e construído a cada vez. Isso conduziu Pagès (1976) a aproximar-se do campo clínico e, consequentemente, a elaborar o método da intervenção psicossociológica.

Tal proposta teórico-metodológica favorece descobertas e coprodução de sentido do trabalho, em que o pesquisador rompe com a posição de detentor do conhecimento e se engaja em uma relação de cooperação, em um projeto comum, no intuito de conferir a coprodução de significados ao trabalho. Por esse prisma, a intervenção não está circunscrita apenas na evolução e na resolução de situações problemáticas, mas cabe a ela também auxiliar na elucidação dos processos organizacionais em geral. Essa relação encontra-se na base da compreensão do mundo do trabalho e do sujeito trabalhador; daí a importância da experiência dos trabalhadores na compreensão e elaboração de conhecimentos nos processos coletivos. Para Lèvy et al. (2001): “...quanto mais houver saber, mais a ação é eficaz e pertinente” (p. 206).

Nesse tipo de intervenção, o pesquisador atua como um agente que interage, constitui e sofre influências do meio em que está inserido, enquanto a intervenção também deve ser influenciada por tais aspectos. Assim, o que pode ser considerado um bom método interventivo em determinada situação pode não dar certo em outra. A metodologia existe previamente; no entanto, também é construída e esclarecida à medida que a ação se desenvolve (Dubost, 2001).

Para que isso ocorra é necessário dar liberdade e responsabilidade aos grupos e aos sujeitos (atores sociais). Inicialmente, a intervenção psicossociológica visa permitir às pessoas falarem sobre sua vida cotidiana, sofrimentos e esperanças. Posteriormente, questões como estrutura da organização, processo de trabalho, hierarquia e problemas decorrentes disso entram nas discussões (Enriquez, 2001). Todas as questões referentes a esses aspectos deverão apontar para possíveis resoluções de problemas que permeiam o discurso do trabalhador.

As organizações recalcam desejos, linguagem e relações em virtude da produtividade, controle e rendimento, o que conduz os indivíduos a se tornarem executadores submissos em vez de "atores sociais". Portanto, essa proposta consiste, antes de tudo, na liberdade de expressão de todos, bem como no engajamento para a transformação a partir da conscientização.

\section{Considerações finais}

De fato, o mundo está em constante transformação e - hoje como nunca antes - essas transformações e mudanças ocorrem de maneira mais acelerada, razão pela qual é necessário cada vez mais o desenvolvimento de uma complexa rede de conhecimento para apreendê-lo. Aqui destacamos o mundo do trabalho, o que faz com que as Clínicas do Trabalho ganhem destaque.

Dentro dessa proposta clínica, o diálogo heterogêneo entre duas teorias que buscam entender o mundo do trabalho contribui, ao mesmo tempo, para o desenvolvimento teórico, prático e da área da Psicologia do Trabalho como um todo. Defender conceitos próprios é diferente de atacar as bases teóricas de outra teoria. Construir-se a partir do contato com uma teoria diferente é onde está toda lucidez das Clínicas do Trabalho.

Quando se propõem alguns diálogos e debates entre a Psicodinâmica do Trabalho e a Psicossociologia, é perceptível que ambas reconhecem e validam, em seu próprio escopo teórico, alguns conceitos desenvolvidos pela outra teoria. Para isso, é necessário referenciar de onde provém aquela determinada ideia ou expressão, a fim de guiar o leitor e reconhecer as construções de tais teorias. Além disso, o fato de que tanto a Psicodinâmica do Trabalho quanto a Psicossociologia possuírem bases teóricas psicanalíticas em comum facilita os diálogos teóricos entre elas. 
Exemplo disso, podemos citar o conceito de ressonância simbólica, desenvolvido por Dejours (1992b), com base na Psicanálise. Resumidamente, trata-se da relação entre a situação de trabalho atual e a situação do teatro interno herdado do passado (história, infância, fantasias do sujeito). $\mathrm{O}$ encontro, segundo o autor, entre a dimensão sincrônica e a dimensão diacrônica.

Como a Psicossociologia considera o trabalho como um palco onde atuam ao mesmo tempo e dialeticamente a relação consigo próprio, a relação com o outro e a relação com o real, ela se referencia à ressonância simbólica para explicar o sentido assumido pelo trabalho em relação à história de vida do sujeito (Lhuilier, 2005).

Outro exemplo é o conceito de reconhecimento. Inicialmente o conceito de reconhecimento (Lima, 2013) explorado pela Psicodinâmica do Trabalho se referencia à importância de o sujeito ter seu trabalho reconhecido pelos seus pares e/ou chefes. O reconhecimento seria a forma da retribuição simbólica advinda da contribuição dada pelo sujeito, pelo engajamento de sua subjetividade e inteligência no trabalho. Esta retribuição se apresenta em duas dimensões: reconhecimento no sentido de constatação, que representa a realidade da contribuição individual à organização do trabalho, e o reconhecimento no sentido de gratidão pela contribuição dos trabalhadores dada à organização do trabalho (Lima, 2013).

A Psicossociologia utiliza-se desse entendimento e expande essa possibilidade ao afirmar que, além da referência psicodinamicista, o reconhecimento (Carreteiro, 2001) também pode advir do próprio trabalhador, que reconhece aquilo que faz como algo maior, algo vinculado à importância social. "Será, portanto, a partir do reconhecimento de nosso lugar de atores sociais (enquanto sujeitos individuais ou coletivos), capazes de contribuir, seja para a evolução social, seja para a sua involução, que poderemos reconhecer nossas possibilidades instituintes" (Carreteiro, 2001, p. 108). O sujeito, ao assumir esse lugar, admitirá o trabalho como um construtor de identidade e de realização pessoal.

Já em relação ao conceito de pesquisador-clínico, ambas utilizam essa denominação, considerando raízes comuns para defini-la. E independentemente da teoria, o pesquisadorclínico deve se basear na escuta sensível indissociável da (inter)subjetividade do sujeito, tomando sua prática como um compromisso ético, social e político. Deve haver envolvimento afetivo e subjetivo tanto do pesquisador como do trabalhador e do empregador. Contudo, o que as diferencia é a postura adotada pelo pesquisador-clínico na intervenção em campo.

Para a Psicodinâmica do Trabalho, o pesquisador-clínico (Dejours, 1992a) deve fazer parte do grupo e dividir seus valores, mas deve manter algumas diferenças e se posicionar como detentor de conhecimento, assumindo o poder que lhe é atribuído pelo grupo. Ao assumir essa posição, ele vai conduzir o processo em conjunto com os trabalhadores. Cabe a ele ser o agente da mudança. O seu objetivo é promover e potencializar subjetiva e coletivamente a tomada de consciência em relação à organização do trabalho e à sua redisposição.

Já para a Psicossociologia, o pesquisador-clínico (Pagès, 1976) deve ser parte do grupo, sem diferenças de função ou valores. Seu papel é participar do grupo de forma espontânea, não se excluir de qualquer questão e cooperar com a atividade coletiva de transformação e elucidação. Não cabe a ele fazer progredir a pesquisa ou a mudança, o que fica a cargo do coletivo e, para tanto, ele precisa renunciar ao poder que lhe é atribuído.

Após esses breves diálogos conceituais, podemos afirmar que não foi objetivo nosso determinar uma teoria ou uma metodologia melhor do que a outra para ser empregada, seja em campo, seja na análise dos dados. Cabe ao leitor, ao curioso pelos métodos que "rompem" com os modelos tradicionais tecnicistas de atuação do Psicólogo no contexto do trabalho, preferir, optar, se sentir tocado pela a proposta com que se identifique mais.

Queremos deixar clara aqui a importância do diálogo teórico heterogêneo para as abordagens clínicas, seja qual for a opção do leitor. Além disso, alertamos e afirmamos - mais 
uma vez - a inviabilidade de se trabalhar com duas ou mais metodologias em uma mesma intervenção.

Sabemos, ainda, que não será este artigo quem dará todas as diretrizes e informações para isso - nem mesmo é a nossa intenção. Contudo, acreditamos que os aspectos abordados possam levantar curiosidades, mobilizar conteúdos que levem o leitor a buscar mais sobre as teorias e metodologias aqui abordadas. Além disso, colocar duas teorias em debate e traçar paralelos teóricos e metodológicos entre elas pode contribuir para o desenvolvimento da própria Psicologia do Trabalho, bem como facilitar o acesso a informações pertinentes a quem se interessar pela área.

\section{Referências}

Amado, G. \& Enriquez, E. (2011). Psicodinâmica do trabalho e psicossociologia. In P. F. Bendassolli \& L. A. P. Soboll (Orgs.), Clínicas do trabalho: novas perspectivas para compreensão do trabalho na atualidade. São Paulo: Atlas.

Amado, G. \& Lhuillier, D. (2014). A atividade no centro da intervenção psicossociológica. In P. F. Bendassolli \& L. A. P. Soboll (Orgs.), Métodos de pesquisa e intervenção em psicologia do trabalho (pp. 33-60). São Paulo: Atlas.

Bardin, L. (1970). Análise de conteúdo. Lisboa: Edições 70.

Bendassolli, P. \& Soboll, L. A. (Orgs.) (2011). Clínicas do trabalho: novas perspectivas para compreensão do trabalho na atualidade. São Paulo: Atlas.

Carreteiro, T. C. (2001). Psicossociologia em exame. In A. Lèvy, A. Nicolaï, E. Enriquez, \& J. Dubost (Orgs.), Psicossociologia: análise social e intervenção. Belo Horizonte: Autêntica.

Carreteiro, T. C. \& Barros, V. A. (2014). Intervenção psicossociológica. In P. F. Bendassolli \& L. A. P. Soboll (Orgs), Métodos de pesquisa e intervenção em psicologia do trabalho (pp. 101-128). São Paulo: Atlas.

Clot, Y. (2007). A função psicológica do trabalho. Petrópolis: Vozes.

Dejours, C. (2007). Psicodinâmica do trabalho na pós-modernidade. In A. M. Mendes, S. C. Cruz, \& E. P. Facas (Orgs.), Diálogos em psicodinâmica do trabalho. Brasília: Paralelo 15.

Dejours, C. (1992a). A loucura no trabalho: estudo de psicopatologia do trabalho (5. ed., Trad. A. I. Paraguay e L. L. Ferreira). São Paulo: Cortez-Oboré.

Dejours, C. (1992b). Uma nova visão do sofrimento psíquico nas organizações. In J. F. Chanlat (Coord.), O indivíduo na organização: dimensões esquecidas (Org. Ofélia de Lanna Sette Torres. Trad. A. M. Rodrigues et. al.). São Paulo: Atlas.

Dejours, C. \& Begué, F. (2010). Suicídio no trabalho: o que fazer? (Trad. Franck Soudant). Brasílio: Paralelo 15.

Demo, P. (2000). Metodologia do conhecimento científico. São Paulo: Atlas.

Dubost, J. (2001). Notas sobre a origem e evolução de uma prática de intervenção psicossociológica. In A. Lèvy, A. Nicolaï, E. Enriquez, \& J. Dubost (Orgs.), Psicossociologia: análise social e intervenção. Belo Horizonte: Autêntica.

Enriquez, E. (2001). Da formação e da intervenção psicossociológicas. In A. Lèvy, A. Nicolaï, E. Enriquez, \& J. Dubost (Orgs.), Psicossociologia: análise social e intervenção. Belo Horizonte: Autêntica.

Ferreira, J. B. (2013). Sujeito. In F. O. Vieira, A. M. Mendes, \& A. R. C. Merlo (Orgs.), Dicionário crítico de gestão e psicodinâmica do trabalho (pp. 451-455). Curitiba: Juruá.

Gaulejac, V. (2001). Psicossociologia e sociologia clínica. In J. N. G. Araújo \& T. C. Carreteiro (Orgs.), Cenários sociais e abordagem clínica (pp. 35-47). São Paulo: Escuta; Belo Horizonte. Fumec.

Lèvy, A., Nicolaï, A., Enriquez, E. \& Dubost, J. (2001). Psicossociologia: análise social e intervenção. Belo Horizonte: Autêntica.

Lhuillier, D. (2011). Filiações teóricas das clínicas do trabalho. In P. F. Bendassolli \& L. A. P. Soboll (Orgs.), Clínicas do trabalho: nova perspectiva para compreensão do trabalho na atualidade (pp. 22-58). São Paulo: Atlas.

Lhuillier, D. (2005). Trabalho. In J. Barrus-Michel, E. Enriquez, \& A. Lèvy (Orgs.), Dicionário de psicossociologia. Lisboa: Climepsi. 
Lima, S. C. C. (2013). Reconhecimento no trabalho. In F. O. Vieira, A. M. Mendes, \& A. R. C. Merlo (Orgs.), Dicionário crítico de gestão e psicodinâmica do trabalho (pp. 351-355). Curitiba: Juruá.

Mendes, A. M. \& Araújo, L. K. R. (2012). Clínica psicodinâmica do trabalho: o sujeito em ação. Curitiba: Juruá.

Mendes, A. M., Cruz, S. C., \& Facas, E. P. (Orgs.) (2007). Diálogos em psicodinâmica do trabalho. Brasília: Paralelo 15.

Pagès, M. (1976). A vida afetiva dos grupos: esboço de uma teoria da relação humana (Trad. L. L. Ribeiro). São Paulo: Vozes e Edusp.

Sainsalieu, R. (2005). Actor. In J. Barrus-Michel, E. Enriquez, \& A. Lèvy (Orgs.), Dicionário de psicossociologia. Lisboa: Climepsi.

Schwartz, Y. \& Durrive, L. (2007). Trabalho e ergologia: conversas sobre a atividade humana.(Trad. J. Brito \& M. Athayde). Niterói: EDUFF.

Vieira, F. O., Mendes, A. M., \& Merlo, A. R. C. (2013). Dicionário crítico de gestão e psicodinâmica do trabalho. Curitiba: Juruá.

\section{Endereço para correspondência}

solderamartins@yahoo.com.br

Recebido em: 15/01/2017

Revisado em: 12/07/2017

Aprovado em: 19/07/2017 